\title{
Dynamic presupposition of want and polarity sensitivity*
}

\author{
Julie Goncharov \\ Georg-August University of Göttingen / \\ University of Toronto
}

\begin{abstract}
In this paper, I argue that content of some presuppositions is determined dynamically. In particular, it is shown that the presupposition of want in control constructions depends on the interpretation of an action in the complement clause. Different presuppositional content of sentences with want is argued for using new and known observations about licensing of Polarity Sensitive Items. I propose to capture the dynamic nature of the presupposition of want using the AGM paradigm for belief revision (Alchourrón, Gärdenfors \& Makinson 1985). Finally, I show that sensitivity to the interpretation of an action as intentional versus accidental is not specific to polarity system, but can be found across different domains of the grammar in many unrelated languages.
\end{abstract}

Keywords: presuppositions, desire predicates, belif revision, Polarity Sensitive Items, actions, intentional, accidental

\section{Introduction}

In her seminal paper, Heim (1992) proposes that want has a doxastic modal base and argues that sentences of the form ' $x$ want $\phi$ ' presuppose that the attitude holder $x$ considers the prejacent $\phi$ and its negation $\neg \phi$ possible, see (1a). Twenty years later, Romoli (2012) points out that (1a) is incompatible with current semantic/pragmatic accounts of strong Negative Polarity Items (NPIs) (e.g., Gajewski 2011; Chierchia 2013) and proposes a weaker conditional presupposition in (1b).

(1) ' $x$ want $\phi$ ' is defined only if:
a. $\diamond^{B_{x}} \phi \wedge \diamond^{B_{x}} \neg \phi$
( $\phi$ and $\neg \phi$ are doxastic possibilities for $x$ )
b. $\diamond^{B_{x}} \phi \rightarrow \diamond^{B_{x}} \neg \phi$
(if $\phi$ is a doxastic possibility for $x$, so is $\neg \phi$ )

In this paper, we discuss new and known observations concerning licensing of Polarity Sensitive Items (PSIs) in the complement of want. The data show that

* I am especially grateful to Lavi Wolf and Gillian Ramchand for helpful comments and suggestions regarding the ideas reported here. I am also thankful to the audiences of OASIS 2, GLOW 43, and SALT 30 for stimulating questions and discussion. I would also like to wholeheartedly thank Hedde Zeijlstra for his support. All errors are my own. 
acceptability of PSIs in these constructions is sensitive to the interpretation of the action as intentional versus accidental (section 2). Based on these data, I argue that both (1a) and (1b) are inadequate. To account for the facts, we need want to have a presupposition whose content changes depending on the nature of the action in the complement clause of want (section 3).

I propose to model this change of presuppositional content using the AGM paradigm for belief revision (e.g., Alchourrón et al. 1985). The mechanism of belief revision ensures that all (relevant) beliefs of the attitude holder, including his beliefs about the nature of the action, are taken into consideration when the doxastic modal base of want is determined. By allowing the resulting belief state to be different from the initial belief state, it makes the presupposition of want dynamic. Consequently, we will see that want has different presuppositions when it combines with intentional versus accidental actions, which explains different acceptability of PSIs in these constructions (section 4).

We close by discussing some previous analyses of the relevant data (section 5) and by looking at other grammatical phenomena sensitive to the interpretation of an action as intentional versus accidental (section 6 ). The later discussion illustrates that the effect is wide-spread and touches different domains of the grammar. Thus, the observations discussed in this paper are part of a bigger picture where interpretation of an action as intentional versus accidental plays central role. Section 7 concludes.

\section{Licensing of PSIs in the complement of want}

\subsection{Positive Polarity Items in the complement of want}

Indefinites, such as someone, something, and some NP, are Positive Polarity Items (PPIs), in that they cannot be interpreted under the immediate scope of clause-mate negation (Klima 1964; Baker 1970; van der Wouden 1997; Nicolae 2012; Homer to appear; a.o.). This is illustrated in (2) for a simple sentence. The unavailability of the reading in (2a) is called anti-licensing of PPIs.

(2) John didn't call someone.

$(*$ not $>$ some $/ \sqrt{ }$ some $>$ not $)$

a. cannot mean: John called nobody.

(not $>$ some)

b. can mean: There is a specific person whom John didn't call. (some $>$ not)

Szabolcsi (2004) observes that the ability of PPIs to scope under negation in control constructions with want is sensitive to interpretation of an action in the complement clause. When the action is interpreted as intentional, some cannot have a narrow scope reading, as in (3a). However, with accidental actions, some can be interpreted under negation, see (3b). 
Dynamic presupposition of want and polarity sensitivity
a. I don't want to call someone/eat something. (*not $>$ some $/ \sqrt{ }$ some $>$ not $)$
b. I don't want to offend someone/break something. ( $\checkmark$ not $>$ some $/ \checkmark$ some $>$ not $)$

(Szabolcsi 2004: fn.10)

To probe the difference between intentional versus accidental actions, let us consider call and offend. Intuitively, calling someone is the action that is initiated intentionally and that is under full control of the agent. Offending, on the other hand, oftentimes is not initiated intentionally. Moreover, even when offending is initiated intentionally, the outcome is not under agent's control (in part, the outcome depends on the psychological state of the offendee). We can formulate this difference in terms of agent's beliefs about the action. If one decides to call Mary, he believes that he will succeed in calling her (note that this is different from succeeding in reaching Mary), whereas if one decides to offend Mary, he can at the same time believe that despite all the effort, Mary might not get offended. To illustrate this contrast in beliefs of the agent of the action, let us look at the sentences in (4). Example (4a) feels contradictory, because an intention to call Mary is inconsistent with the expectation that one will not call her. By contrast, an intention to offend Mary is compatible with the belief that Mary will not be offended, thus, (4b) is not contradictory.

(4) a. \# I intend to call Mary, but I don't (actually) expect that I'll call her.

b. I intend to offend Mary, but I don't (actually) expect that I'll offend her.

Another test to tell apart intentional versus accidental actions is the presence or absence of a weakness of will reading in sentences like (5). In addition to an accidentality reading, (5a) with call has a clear weakness of will reading, which (5b) with offend lacks. ${ }^{1}$ In what follows, we will be using the weakness of will test to distinguish intentional actions from accidental actions as the effect is very robust.
a. I didn't want to call Mary, but I did.
$(\checkmark$ weakness of will)
b. I didn't want to offend Mary, but I did.
(*weakness of will)

Szabolcsi's (2004) observation is further corroborated by the fact that when call is interpreted in the context of pocket dialing, as in (6), or expressions of accidentality, such as accidentally and by mistake are added, as in (7), some can be interpreted below negation.

(6) Context: You are walking along with your friend John and see him switching off his phone before putting it into the pocket.

1 Weakness of will is a widely discussed topic in the philosophy of action, see Stroud \& Svirsky 2019 for a recent overview. 
You: Why are you switching off your phone?

John: Oh! I don't want to call someone.

$(\checkmark$ not $>$ some $)$

(7) I don't want to call someone accidentally/by mistake.

$(\sqrt{ }$ not $>$ some $)$

The same sensitivity of PPIs to the interpretation of an action as intentional versus accidental is attested in many unrelated languages, including Hungarian, Polish, Romanian, and Russian (see Szabolcsi 2010 for the data).

\subsection{Negative Polarity Items in the complement of want}

Szabolcsi's (2004) observation can be transported to the realm of NPIs. However, as we will see shortly, not all NPIs show sensitivity to the interpretation of an action. The well-known distinction between strong and weak NPIs manifests itself here as well. Expressions, such as a red cent, a damn thing, and a living soul, are strong NPIs (or minimizers). Their distribution is more restricted compared to weak NPIs, such as any and ever. In particular, strong NPIs, but not weak NPIs, are restricted to Anti-Additive (AA) contexts rather than simple Downward Entailing (DE) contexts, see (8). ${ }^{2}$ Moreover, strong NPIs, but not weak NPIs, have a locality restriction, see (9) (Zwarts 1998; van der Wouden 1997; Jackendoff 1995; Szabolcsi 2004; Gajewski 2007, 2011; Giannakidou 2011; Collins \& Postal 2014; a.o.).

a. Nobody gave anything/a red cent to the beggar.

b. Less than five people gave anything/*a red cent to the beggar. (not AA)

a. Nobody gave John any money/a red cent.

b. Nobody [ who gave John any money/*a red cent ] is here.

The novel observation that interests us here is that in the complement of want, strong NPIs appear to be less acceptable with accidental action like lose and win than with fully intentional actions like spend and give, compare (10) with (11). This is a mirror image of the pattern we found with PPIs in the previous section.

(10) a. The company wants to harvest new ideas but doesn't want to spend a red cent on this.

b. I don't want to give a red cent to the beggar.

a. ?? This investment is too risky. I don't want to lose a red cent on it.

b. ?? I don't want to win a red cent in this lottery.

2 A function $\mathrm{f}$ is $\mathrm{DE}$ iff for any arbitrary $\mathrm{A}, \mathrm{B}$, if $\mathrm{A} \subseteq \mathrm{B} \rightarrow \mathrm{f}(\mathrm{B}) \subseteq \mathrm{f}(\mathrm{A})$. A function $\mathrm{f}$ is $\mathrm{AA}$ iff for any arbitrary $\mathrm{A}, \mathrm{B}, \mathrm{f}(\mathrm{A} \cap \mathrm{B})=\mathrm{f}(\mathrm{A}) \cup \mathrm{f}(\mathrm{B})$. AA operators, such as not and nobody, form a proper subset of DE operators, such as at most and less than. 
Dynamic presupposition of want and polarity sensitivity

Interestingly, weak NPIs are not affected by the interpretation of an action. As illustrated in (12) and (13), in the complement of want, weak NPIs are equally acceptable with intentional and accidental actions.

(12) a. The company wants to harvest new ideas but doesn't want to spend any money on this.

b. I don't want to give any money to the beggar.

(13) a. This investment is too risky. I don't want to lose any money on it.

b. I don't want to win any money in this lottery.

That spend and give are different from lose and win can be shown using the weakness of will test introduced above. Like call, spend and give in (14) give rise to a clear weakness of will (or coercion) reading. By contrast, lose and win do not have a weakness of will reading because their success is partly due to luck, see (15).

(14) a. I didn't want to spend $\$ 500$ on new books, but I did. ( $\checkmark$ weakness of will)

b. I didn't want to give $\$ 100$ to John, but I did. ( $\quad$ weakness of will)

(15) a. I didn't want to lose money in this investment, but I did. (*weakness of will)

b. I didn't want to win this game, but I did. (*weakness of will)

To summarize the data we saw in this section, we make three observations concerning licensing of PSIs in the complement of want: (i) PPIs are anti-licensed in intentional contexts, but not in accidental ones; (ii) strong NPIs are less acceptable in accidental contexts than in intentional contexts (mirror image); and (iii) weak NPIs are not sensitive to the interpretation of an action as intentional versus accidental.

\section{Dynamic presupposition of want}

The data discussed in section 2 have received little attention in the literature. The contrast in licensing of strong NPIs in the complement of want, partially repeated in (16), is especially problematic for current analyses of PSIs.

(16) a. I don't want to give a red cent to the beggar.

b. ?? I don't want to win a red cent in this lottery.

Syntactic accounts, arguing that strong NPIs need clause-mate negation and thus, in bi-clausal constructions can be licensed only under neg-raising predicates (e.g., Collins \& Postal 2014), predict both (16a) and (16b) to be fully acceptable. This is 
because want is a neg-raising predicate. ${ }^{3}$ Semantic accounts, attributing licensing of strong NPIs to the strength of the licensing operator or environment (which has to be AA), also predict (16a) and (16b) to be grammatical. This is because anti-additivity in these sentences is derived as a consequence of the neg-raising property of want (Gajewski 2005, 2007; Romoli 2012; a.o.). Recently, Gajewski (2011) has argued for a modification of the semantic approach to NPI licensing, suggesting that the difference between strong and weak NPIs is that the former, but not the latter, are sensitive to the monotonicity of non-truth-conditional content of the sentence. In other words, weak NPIs are licensed when the assertion is DE, whereas strong NPIs, in addition, require that scalar implicatures and presuppositions of the sentence be DE. As a brief illustration, let us consider licensing of the strong NPI punctual until and weak NPI any in the restrictor of every, see (17). Every is AA in its first argument. ${ }^{4}$ Therefore, the unacceptability of until in (17a) cannot be explained by the standard semantic accounts. According to Gajewski's (2011) proposal, the unacceptability of until in (17a) is due to the presence of the existential presupposition of the relative clause in (18), which is Upward-Entailing (UE). As weak NPIs are not sensitive to the monotonicity of presuppositions, a similar presupposition of (17b) does not interfere with licensing of any. ${ }^{5}$

a. * Everyone who left until Tuesday missed the class.

b. Everyone who read any article today should raise their hand.

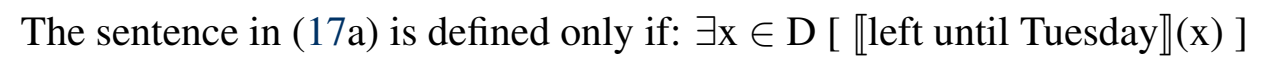

Extending Gajewski's (2011) approach to strong NPIs in the complement of want, we see that neither Heim's (1992) presupposition in (1a) nor Romoli's (2012) presupposition in (1b), repeated in (19a) and (19b) respectively, can account for the contrast in licensing of a red cent in (16).

' $x$ want $\phi$ ' is defined only if:
a. $\diamond^{B_{x}} \phi \wedge \diamond^{B_{x}} \neg \phi$
( $\phi$ and $\neg \phi$ are doxastic possibilities for $x$ )
b. $\diamond^{B_{x}} \phi \rightarrow \diamond^{B_{x}} \neg \phi$
(if $\phi$ is a doxastic possibility for $x$, so is $\neg \phi$ )

3 Neg-raising predicates, such as believe, think, expect, and want, when negated give rise to a reading where negation is interpreted in the embedded clause (Fillmore 1963; Bartsch 1973; Gajewski 2005, 2007; Collins \& Postal 2014; a.o.). That want is a neg-raising predicate is illustrated by the possibility of the following inference: Mary doesn't want to dance. $\rightsquigarrow$ Mary wants not to dance.

4 To verify this, we need to check the following equivalence (see fn. 2): Every blonde or red-haired student came to class. $\Rightarrow / \Leftarrow$ Every blonde student came to class and every red-haired student came to class.

5 For the full formal account using exhaustification see Gajewski 2011; Chierchia 2013; among others. 
Dynamic presupposition of want and polarity sensitivity

The presupposition in (19a) makes a red cent in (16a) and (16b) equally unacceptable because the first conjunct in (19a) is not DE. On the other hand, (19b) predicts that $a$ red cent in (16a) and (16b) is equally acceptable since in the antecedent and in the consequent, a red cent appears in a DE environment.

However, Gajewski-style approach (unlike the two other approaches) can be used to capture the contrast in (16). What we need is to be able to derive different presuppositions for want with intentional versus accidental actions such that accidentality intervenes with strong NPI licensing. The desired presuppositions are shown in (20).
a. ' $x$ not want $\phi^{\text {intentional' }}$ is defined only if $\square^{B_{x}} \neg \phi$
b. ' $x$ not want $\phi^{\text {accidental' }}$ is defined only if $\diamond^{B_{x}} \phi \wedge \diamond^{B_{x}} \neg \phi$

Developing different presuppositions for want depending on the action in the complement clause will be our task in the next section. Here, it is important to point out that this kind of approach is supported by the asymmetry in acceptability of strong and weak NPIs in accidental contexts, compare (11) with (13) from section 2. The lack of the effect with weak NPIs will be straightforwardly explained as they are not sensitive to the monotonicity of presuppositional content.

The solution sketched here can also be extended to the contrast in PPI antilicensing in (3) if we assume that the UE presupposition created by accidental actions is sufficient for allowing some to be interpreted under negation. This assumption is supported by the fact that some is not anti-licensed under DE quantifiers with UE scalar implicatures, such as few and at most, see (21) (e.g., Szabolcsi 2004).

At most five boys called some.

$(\checkmark$ at most $>$ some $)$

\section{Proposal and predictions}

\subsection{Intentional versus accidental actions}

Before we see how to derive different presuppositions for want, we need to formalize agent's beliefs about intentional and accidental actions. We start with a terminological note. First, we need to distinguish between actions that can be initiated intentionally and those that cannot. This distinction can be tested using rationale clauses introduced by in order to (Farkas 1988). Actions that can be initiated intentionally can be modified by in order to, see (22a). By contrast, actions that cannot be initiated intentionally are incompatible with in order to, see (22b). This distinction, however, is not enough because it does not allow us to separate verbs like call/eat from offend/break. The latter can (but don't have to) be initiated intentionally and in such cases, can be modified by in order to, see (23). 
(22) a. Mary refused to eat in order to become thinner.

b. \# Mary forgot to eat in order to become thinner.

a. The driver called the police in order to file a report.

b. Eve ate the fruit in order to fulfill forbidden desires.

c. He will offend people in order to achieve his goal.

d. He broke the handle in order to enter the room.

The second distinction we need to make is that between controlled and noncontrolled actions. This distinction refers to whether the agent controls the outcome of his action. This distinction can be tested using the weakness of will test, discussed above, see (5), (14), and (15). Actions that give rise to the weakness of will inference are controlled by the agent. Actions that do not have a clear weakness of will inference are not fully controlled by the agent.

We say that an action is intentional if it is initiated intentionally and is controlled by the agent, else the action is accidental (which includes actions that are initiated intentionally, but are non-controlled, and actions that are not initiated intentionally, i.e., unintentional). This division draws the correct line between predicates like call, give, and spend, on the one hand, and offend, win, and forget, on the other hand.

We define intentional actions as actions in which the agent $x$ believes that if he acts so as to bring about $\phi$, the state of affairs described by $\phi$ obtains and similarly for $\neg \phi$, see (24a). An action is accidental when it is not intentional, that is to say, when the negation of (24a) holds, see (24b). ${ }^{6}$ Throughout this paper, we use $\phi$ to represent the proposition that describes the action in the complement of want and $\psi$ to denote a complex proposition that the agent acts so as to bring about $\phi$.
a. Intentional actions: $\square^{B_{x}}((\psi \rightarrow \phi) \wedge(\neg \psi \rightarrow \neg \phi))$
b. Accidental actions: $\neg \square^{B_{x}}((\psi \rightarrow \phi) \wedge(\neg \psi \rightarrow \neg \phi))$

\subsection{Belief revision}

To obtain different presuppositions for intentional and accidental actions, we use tools from dynamic doxastic logic. In particular, we assume the AGM paradigm for belief revision enriched with standard modal operators $\square^{B_{x}}$ (and its dual $\diamond^{B_{x}}$ ) and two additional principles concerning when belief revisions apply (Alchourrón et al. 1985; Lindström \& Rabinowicz 1999; van Ditmarsch, van der Hoek \& Kooi 2008). ${ }^{7}$

6 We assume normal course of events, that is to say, no deviant chain effects or other classical problems for intentions (Davidson 1967; Bratman 1987; a.o.). It is also important to note here that we talk not of actions simpliciter but of descriptions of actions (e.g., Davidson 2001; Gorr \& Horgan 1982).

7 Nothing hinges on the choice of a particular approach to belief revision. Other mechanisms can be assumed as long as they allow to expand and contract a belief set. For expository purposes, we stay with the simplest and most transparent AGM paradigm here. 
Dynamic presupposition of want and polarity sensitivity

The AGM-approach uses ordinary mathematical English to discribe belief revisions. It defines two operations: expansion and contraction on a belief set $\mathrm{K}$ (i.e., a set of propositions). As is customary, we assume that $\mathrm{K}$ is closed under a consequence operation $\mathrm{Cn}(\cdot){ }^{8}$ The operation of expansion $\oplus$ simply adds the proposition $\alpha$ to $\mathrm{K}$, as defined in (25). The operation of contraction $\ominus$ removes $\alpha$ from $\mathrm{K}$ and is defined using a number of postulates in (26). These postulates ensure that with contraction, nothing is added to $\mathrm{K}$, see (26a), that nothing happens if $\alpha$ is not in $\mathrm{K}$, see (26b), that $\alpha$ must be removed unless $\alpha$ is a tautology, see (26c), that contraction is recoverable, see (26d), and that contraction does not depend on the syntactic representation of $\alpha$, see (26e). ${ }^{9}$

$$
\text { Expansion: } \mathrm{K} \oplus \alpha=\mathrm{Cn}(\mathrm{K} \cup\{\alpha\})
$$

\section{Contraction:}

$$
\begin{aligned}
& \text { a. } \mathrm{K} \ominus \alpha \subseteq \mathrm{K} \\
& \text { b. If } \alpha \notin \mathrm{K} \text {, then } \mathrm{K}=\mathrm{K} \ominus \alpha \\
& \text { c. If } \top \notin \mathrm{Cn}(\{\alpha\}) \text {, then } \alpha \notin \mathrm{K} \ominus \alpha \\
& \text { d. If } \alpha \in \mathrm{K} \text {, then } \mathrm{K} \subseteq(\mathrm{K} \ominus \alpha) \oplus \alpha \\
& \text { e. If } \operatorname{Cn}(\{\alpha\})=\mathrm{Cn}(\{\beta\}) \text {, then } \mathrm{K} \ominus \alpha=\mathrm{K} \ominus \beta
\end{aligned}
$$

contraction

minimal action

success

recovery

extensionality

The operation of belief revision $\circledast$ is defined in terms of expansion and contraction, which is known as the Levi Identity, see (27). According to (27), in order to revise $\mathrm{K}$ with $\alpha$, we first contract $\neg \alpha$ from $\mathrm{K}$ and then expand $\mathrm{K}$ with $\alpha$.

$$
\text { The Levi Identity: } \mathrm{K} \circledast=(\mathrm{K} \ominus \neg \alpha) \oplus \alpha
$$

As mentioned above, we enrich the simple propositional logic of AGM with two modal operators $\square^{B_{x}}$ and its dual $\diamond^{B_{x}}$, where $\mathrm{B}$ is a doxastic accessibility relation which is serial, transitive, and shift-reflexive (i.e., a relation $\mathrm{R}$ is shift-reflexive iff for any w, $\mathrm{w}^{\prime}$ such that $\mathrm{wRw}^{\prime}$, also $\mathrm{w}^{\prime} \mathrm{Rw}^{\prime}$, see Kaufmann 2019 p. 653). ${ }^{10}$

We also add two principles in (28) that characterise when belief revision is applied in natural language. According to (28a), a belief set $\mathrm{K}$ (which we assume

$8 \mathrm{Cn}(\cdot)$ is an operation of logical consequence introduced by Tarski. $\mathrm{Cn}(\cdot)$ takes sets of propositions to sets of propositions and satisfies the following three conditions: (i) for any set $\mathrm{X}, \mathrm{X} \subseteq \mathrm{Cn}(\mathrm{X})$, (ii) for any set $X, C n(X)=\operatorname{Cn}(\operatorname{Cn}(X))$, (iii) for any sets $X$ and $Y, C n(X) \subseteq \operatorname{Cn}(Y)$ whenever $X \subseteq Y$. A set of propositions $\mathrm{A}$ closed under $\mathrm{Cn}(\cdot)$ is such that $\mathrm{A}=\mathrm{Cn}(\mathrm{A})$. We assume that $\mathrm{Cn}$ includes classical tautologies, is compact, and satisfies the rule of introduction of disjunction. A set of propositions $\mathrm{A}$ is consistent (modulo $\mathrm{Cn}$ ) only if for no $a, a \wedge \neg a \in \mathrm{Cn}(\mathrm{A})$.

9 The postulates in (26) are basic postulates for contraction. Other postulates can be added for specific cases.

10 In complex cases, adding introspection to the AGM system can give rise to paradoxes, see Lindström \& Rabinowicz 1999; van Ditmarsch et al. 2008. To overcome these paradoxes, more complex systems are introduced. For the purpose of this paper, a simple system suffices. 
to be consistent) is revised with a proposition $\alpha$ if $\alpha$ is not a contradiction (Revise if consistent!). Otherwise, the result of belief revision is the initial belief set, as in (28b) (Do not revise with contradiction!). The rationale behind (28b) is straightforward: revising $\mathrm{K}$ with a contradiction results in an inconsistent belief set.

(28) Let $\mathrm{K}$ be a belief set as discussed above and $\alpha$ be a formula of the propositional logic defined as follows: $\alpha:=p|\neg \alpha| \alpha \wedge \alpha \mid \square^{B_{x}} \alpha$. Revising K with $\alpha$, written here as $\mathrm{K} \circledast \alpha$, obeys the following principles:

a. If $\perp \notin \mathrm{Cn}(\{\alpha\})$, then $\mathrm{K} \circledast \alpha=(\mathrm{K} \ominus \neg \alpha) \oplus \alpha \quad$ Revise if consistent! b. Otherwise, $\mathrm{K} \circledast \alpha=\mathrm{K}$ Do not revise with contradiction!

In order to obtain different presuppositions for want, we begin by assuming that $\mathrm{K}$ is a neutral belief set. That is to say, for ' $x$ want $\phi$ ', $\mathrm{K}$ is such that $x$ does not believe $\phi$ nor its negation $\neg \phi$ (i.e., $\mathrm{K}=\left\{\diamond^{B_{x}} \phi \wedge \diamond^{B_{x}} \neg \phi\right\}$ ). The proposition $\alpha$ with which $\mathrm{K}$ is revised is a conjunction of three conditions in (29). The decision condition in (29a) is similar to what Condoravdi \& Lauer $(2012,2016)$ call 'effective preferences' (see also the idea of decisive modality in Kaufmann \& Kaufmann 2012; Kaufmann 2019). It requires that when ' $x$ want $\phi$ ' is uttered $x$ 's belief set is updated with the belief that $x$ will act so as to bring about $\phi$ (i.e., $\square^{B_{x}} \psi$ ) and similarly for ' $x$ not want $\phi$ '. In addition to Decision, $\mathrm{K}$ is updated with $x$ 's beliefs about the interpretation of the action in the complement clause, see (29b), and Romoli's (2012) presupposition for want, see (29c).

(29) In want-sentences, a neutral belief set $\mathrm{K}$ is revised with:

a. Decision: $\square^{B_{x}} \psi$ when ' $x$ want $\phi$ ' is uttered or $\square^{B_{x}} \neg \psi$ when ' $x$ not want $\phi^{\prime}$ is uttered

b. Intentional or accidental condition from (24), repeated below, depending on the interpretation of the action in the complement clause

Intentional actions: $\square^{B_{x}}((\psi \rightarrow \phi) \wedge(\neg \psi \rightarrow \neg \phi))$

Accidental actions: $\neg \square^{B_{x}}((\psi \rightarrow \phi) \wedge(\neg \psi \rightarrow \neg \phi))$

c. Romoli's (2012) presupposition for want: $\diamond^{B_{x}} \phi \rightarrow \diamond^{B_{x}} \neg \phi$

Thus, sentences with want can have four possible revisions in (30)-(33). In (30), we see that $\alpha$ is a contradiction, thus the revised set $\mathrm{K} \circledast \alpha$ is identical to the initial belief set K, according to (28b) (Do not revise with contradiction!). The revisions with accidental actions in (31) and (33) result in a larger belief set expanded by a corresponding Decision proposition. The revision in (32) involves contraction which removes $\diamond^{B_{x}} \phi$ and strengthens $\diamond^{B_{x}} \neg \phi$ to $\square^{B_{x}} \neg \phi$. In (32), we use iterative revision instead of revision with conjunction in order to make our formulas more readable. The equivalence is guaranteed because the following postulate can be derived from the postulates above: $\mathrm{K} \circledast(\alpha \wedge \beta) \subseteq(\mathrm{K} \circledast \alpha) \oplus \beta$. 
Dynamic presupposition of want and polarity sensitivity

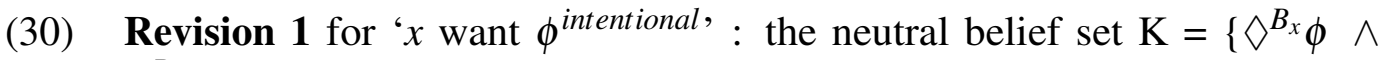
$\left.\diamond^{B_{x}} \neg \phi\right\}$ is revised with $\alpha$ which is the conjunction of:
a. $\square^{B_{x}} \psi$
Decision
b. $\square^{B_{x}}((\psi \rightarrow \phi) \wedge(\neg \psi \rightarrow \neg \phi)) \equiv \square^{B_{x}}(\psi \rightarrow \phi) \wedge \square^{B_{x}}(\neg \psi \rightarrow \neg \phi)$
c. $\diamond^{B_{x}} \phi \rightarrow \diamond^{B_{x}} \neg \phi$
psp of want

$\mathrm{K} \circledast \alpha=\mathrm{K}$ by (28b) Do not revise with contradiction! because $\mathrm{a} \wedge \mathrm{b} \wedge \mathrm{c}$ is a contradiction (in doxastic logic, $\square^{B_{x}}(\psi \rightarrow \phi)$ and $\square^{B_{x}} \psi$ implies $\square^{B_{x}} \phi$ )

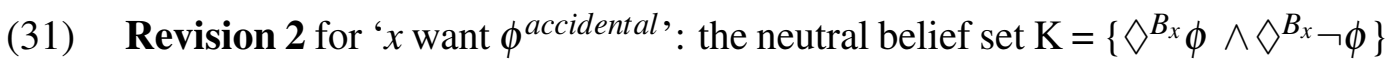
is revised with $\alpha$ which is the conjunction of:
a. $\square^{B_{x}} \psi$
Decision
b. $\neg \square^{B_{x}}((\psi \rightarrow \phi) \wedge(\neg \psi \rightarrow \neg \phi)) \equiv \diamond^{B_{x}}(\psi \wedge \neg \phi) \vee \diamond^{B_{x}}(\neg \psi \wedge \phi)$
c. $\diamond^{B_{x}} \phi \rightarrow \diamond^{B_{x}} \neg \phi$
psp of want

$\mathrm{K} \circledast \alpha=\left\{\diamond^{B_{x}} \phi \wedge \diamond^{B_{x}} \neg \phi\right\} \cup\left\{\square^{B_{x}} \psi\right\}$ by Expansion (note that $\mathrm{K} \circledast \alpha$ entails $\mathrm{b}$ and $\mathrm{c}$ )

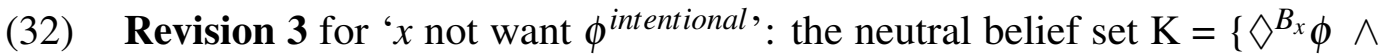
$\left.\diamond^{B_{x}} \neg \phi\right\}$ is revised with $\alpha$ which is the conjunction of:
a. $\square^{B_{x}} \neg \psi$
Decision
b. $\square^{B_{x}}((\psi \rightarrow \phi) \wedge(\neg \psi \rightarrow \neg \phi)) \equiv \square^{B_{x}}(\psi \rightarrow \phi) \wedge \square^{B_{x}}(\neg \psi \rightarrow \neg \phi)$
c. $\diamond^{B_{x}} \phi \rightarrow \diamond^{B_{x}} \neg \phi$
psp of want

$1 . \mathrm{K} \circledast \mathrm{a}=\left\{\diamond^{B_{x}} \phi \wedge \diamond^{B_{x}} \neg \phi\right\} \cup\left\{\square^{B_{x}} \neg \psi\right\}$ by Expansion

$2 . \mathrm{K} \circledast \mathrm{b}=\left(\mathrm{K} \ominus \neg \square^{B_{x}}(\neg \psi \rightarrow \neg \phi)\right) \oplus \square^{B_{x}}(\neg \psi \rightarrow \neg \phi)=$ $=\left\{\diamond^{B_{x}} \neg \phi, \square^{B_{x}} \neg \psi, \square^{B_{x}}(\neg \psi \rightarrow \neg \phi)\right\}=\left\{\square^{B_{x}} \neg \psi, \square^{B_{x}} \neg \phi\right\}$

(only the relevant conjunct from (24a) is used here)

$3 . \mathrm{K} \circledast \mathrm{c}=\mathrm{K} \cup\left\{\diamond^{B_{x}} \phi \rightarrow \diamond^{B_{x}} \neg \phi\right\}=\left\{\square^{B_{x}} \neg \phi, \square^{B_{x}} \neg \psi, \diamond^{B_{x}} \phi \rightarrow \diamond^{B_{x}} \neg \phi\right\}$ by Expansion

(33) Revision 4 for ' $x$ not want $\phi^{\text {accidental' }}$ : the neutral belief set $K=\left\{\diamond^{B_{x}} \phi \wedge\right.$ $\left.\diamond^{B_{x}} \neg \phi\right\}$ is revised with $\alpha$ which is the conjunction of:
a. $\square^{B_{x}} \neg \psi$
Decision
b. $\neg \square^{B_{x}}((\psi \rightarrow \phi) \wedge(\neg \psi \rightarrow \neg \phi)) \equiv \diamond^{B_{x}}(\psi \wedge \neg \phi) \vee \diamond^{B_{x}}(\neg \psi \wedge \phi)$
c. $\diamond^{B_{x}} \phi \rightarrow \diamond^{B_{x}} \neg \phi$
psp of want

$\mathrm{K} \circledast \alpha=\left\{\diamond^{B_{x}} \phi \wedge \diamond^{B_{x}} \neg \phi\right\} \cup\left\{\square^{B_{x}} \neg \psi\right\}$ by Expansion (note that $\mathrm{K} \circledast \alpha$ entails $b$ and $c$ ) 
It is worthwhile to point out here that Revisions 2 and 4 shown above are modelled for actions that are initiated intentionally, but are not fully controlled by the agent, such as offend and win. In these actions, the agent can decide to act so as to bring $\phi$ about, but the success is not guaranteed. That is to say, both $\phi$ and $\neg \phi$ are doxastic possibilities. If an action is unintentional, that is to say the agent takes it possible that he will act so as to bring $\phi$ about and that he will not act so as to bring $\phi$ about, the result of Revisions 2 and 4 is the same - both $\phi$ and $\neg \phi$ are doxastic possibilities. This is because unintentional actions are not controlled by the agent.

The idea behind belief revision when constructing the doxastic modal base of want is fairly simple. When a hearer evaluates the belief state of the attitude holder $x$, he starts with a neutral belief state of $x$ in which both $\phi$ and $\neg \phi$ are possible. Then, the hearer revises this belief state with different composite parts of the sentence which include Romoli's (2012) presupposition of want, the decision on how $x$, who is also the agent of the action in the complement clause, will act, and the nature of the action (intentional versus accidental). The revised belief state of $x$ is the modal base for want. It is also added to Common Ground as a common belief between the speaker and the hearer, which makes it a presupposition (Stalnaker 2002).

In the remainder of this section, I discuss consequences of Revisions 1-4 in some detail, including how they help to account for the data in section 2. Revision 1 in (30) is an 'unsuccessful' revision. This is because $\mathrm{a} \wedge \mathrm{b} \wedge \mathrm{c}$ is a contradiction and by Do not revise with contradiction! in (28b), the revised belief set is the same as the neutral belief set in which $x$ does not believe $\phi$ nor $\neg \phi$.

Incidentally, Revision 1 straightforwardly derives Heim's (1992) stipulation that in cases like (34), when constructing the modal base of want, we do not take into consideration John's intentions about how he is going to act. In other words, the belief state in (34) is a superset of John's beliefs compatible with John's going to the movies and John's not going to the movies tonight. In Heim's (1992) system, the stipulation is needed to avoid Stalnaker's (1984) fallacies, ${ }^{11}$ but no motivation is provided for the stipulation.

$$
\text { (John hired a babysitter because) he wants to go to the movies tonight. }
$$

When an action in the complement of want is accidental (Revisions 2 and 4), the result of the revision is simple expansion by $\square^{B_{x}} \psi$ in case of Revision 2 or $\square^{B_{x}} \neg \psi$ in case of Revision 4, see (31) and (33). Moreover, by Revision 4, we obtain the desired presupposition in (20b) that serves as an intervener for strong NPI licensing and PPI anti-licensing.

11 Stalnaker's (1984) fallacies are unwelcome inferences such as: I want to get well. $\rightsquigarrow$ I want to have been sick. In Heim's (1992) system, the fallacies can be avoided by presupposition failure if ' $x$ want $\phi$ ' presupposes that ' $x$ does not believe $\phi$ nor $\neg \phi$ '. 
Dynamic presupposition of want and polarity sensitivity

Revision 3 in (32) gives us the desired presupposition in (20a). In sentences like ' $x$ not want $\phi^{\text {intentional }}$, the revised belief set contains only the propositions in which the NPIs appears in DE environment, thus, leading to full acceptability of strong NPIs, as well as, anti-licensing of PPIs.

Finally, since weak NPIs are not sensitive to non-truth-conditional content, the interpretation of the action as intentional versus accidental does not affect their acceptability.

\subsection{Predictions}

The proposal outlined above correctly predicts that sensitivity of PSIs to the interpretation of an action as intentional versus accidental is not found in simple unembedded sentences such as (35). In (35a), a red cent is fully acceptable although the action is interpreted as accidental. Similarly, in (35b), some cannot be interpreted under negation although the same accidental action expressed by offend is used as in Szabolcsi's (2004) observation.

a. John didn't win a red cent in this game.

b. John didn't offend someone.

$(*$ not $>$ some $)$

The effect is absent because John's beliefs (including his beliefs about the action) are not under discussion in (35). We do not ascribe an attitude to John, together with his possible decisions on how to act and beliefs about the nature of the action.

However, we can see a reflection of the intentional/accidental distinction in simple sentences as well. Consider, for example, (36). There is something unsettling about (36) if we interpret God in its classical sense as an omniscient and omnipotent being. Isn't it the case that such a being if she intends to win the lottery, would know that she will win it?

? God won the lottery.

Another prediction that our proposal makes concerns strong NPI licensing and PPI anti-licensing in object control constructions, such as I want John to call Mary. In particular, we predict that in such cases, strong NPIs are not fully acceptable and PPIs are not anti-licensed and, when the complement of want is an intentional action. This prediction is borne out at least for English, see (37) and (38). Although the judgments for strong NPIs are less robust than for PPIs, many speakers find the contrast in (37) to be strong.

a. ? I don't want Paul to give a red cent to the beggar.

b. I don't want to give a red cent to the beggar. 
(38) a. I don't want Paul to call someone.

$(\checkmark$ not $>$ some $)$

b. I don't want to call someone.

$(*$ not $>$ some $)$

The lack of effect in object control is explained by the fact that the conditions in (24) are relativized to the agent of the action and in cases where the agent of the action is different from the attitude holder, belief revisions do not derive different presuppositions for want. This is illustrated in (39) and (40) where $x$ is the attitude holder and $y$ is the agent of the action.

(39) Revision $3^{\prime}$ for ' $x$ not want $y$ to $\phi^{\text {intentional' }}$ : the neutral belief set $\mathrm{K}=$ $\left\{\diamond^{B_{x}} \phi \wedge \diamond^{B_{x}} \neg \phi\right\}$ is revised with $\alpha$ which is the conjunction of a $\wedge \mathrm{c}$ :
a. $\square^{B_{x}} \neg \psi$
Decision
b. $\square^{B_{y}}((\psi \rightarrow \phi) \wedge(\neg \psi \rightarrow \neg \phi))$
c. $\diamond^{B_{x}} \phi \rightarrow \diamond^{B_{x}} \neg \phi$
psp of want
$\mathrm{K} \circledast \alpha=\left\{\diamond^{B_{x}} \phi \wedge \diamond^{B_{x}} \neg \phi\right\} \cup\left\{\square^{B_{x}} \neg \psi\right\}$ by Expansion

(40) Revision $4^{\prime}$ for ' $x$ not want $y$ to $\phi^{\text {accidental' }}$ : the neutral belief set $\mathrm{K}=$ $\left\{\diamond^{B_{x}} \phi \wedge \diamond^{B_{x}} \neg \phi\right\}$ is revised with $\alpha$ which is the conjunction of a $\wedge \mathrm{c}$ :
a. $\square^{B_{x}} \neg \psi$
Decision
b. $\neg \square^{B_{y}}((\psi \rightarrow \phi) \wedge(\neg \psi \rightarrow \neg \phi))$
c. $\diamond^{B_{x}} \phi \rightarrow \diamond^{B_{x}} \neg \phi$
psp of want
$\mathrm{K} \circledast \alpha=\left\{\diamond^{B_{x}} \phi \wedge \diamond^{B_{x}} \neg \phi\right\} \cup\left\{\square^{B_{x}} \neg \psi\right\}$ by Expansion $(\mathrm{K} \circledast \alpha$ entails c)

As we see in (39), the belief revision with intentional actions in object control is a simple expansion and the UE conjunct is not removed. Therefore, strong NPIs are not fully acceptable and PPIs are not anti-licensed. The revision in (40) is given to complete the picture.

\section{Previous analyses}

To the best of my knowledge, there are no accounts of the contrasts in NPI licensing in the complement of want that we saw in section 2.2. There are only two existing accounts of Szabolcsi's (2004) observation in section 2.1 to which we turn now. ${ }^{12}$

The first account is a semantic/syntactic proposal in Szabolcsi 2010. Szabolcsi (2010) uses Farkas's $(1988 ; 1992)$ intuition that intentions and agency in the grammar are connected to the presence of the RESP(onsibility) relation defined in (41). Farkas $(1988,1992)$ uses RESP to motivate controller choice in control constructions and explain subjunctive obviation (discussed below).

12 These accounts also aim at explaining weakening of subjunctive obviation, see (48). Zu (2018) also extends her proposal to verbal inflection in Newari, see (49). 
Dynamic presupposition of want and polarity sensitivity

(41) "RESP $(i, s)$ holds between an individual $i$ (initiator) and a situation $s$ just in case $i$ brings $s$ about, i.e., $s$ is the result of some act performed by $i$ with the intention of bringing $s$ about."

(Farkas 1988: 36)

To account for the PPI anti-licensing phenomena, Szabolcsi (2010) postulates a syntactically present non-RESP marker, whose insertion is determined locally on the complement clause. Szabolcsi proposes that non-RESP 'shields' the PPI from negation with accidental actions. 'Shielding' is a term coined by Szabolcsi (2004) to describe the observation that PPIs become acceptable under clause-mate negation when a strong scalar expression, like always or every, intervenes between the PPI and negation, see (42), e.g., Kroch 1979; Szabolcsi 2004. For Szabolcsi, non-RESP in (43) acts similarly to always and every in (42).
a. John doesn't always call someone.
$(\checkmark$ not $>$ always $>$ some $)$
b. John didn't tell everyone something.
$(\checkmark$ not $>$ every $>$ some $)$
I don't want non-RESP to offend someone.
$(\checkmark$ neg $>$ some $)$

Szabolcsi's (2010) proposal faces a number of difficulties. First of all, as Szabolcsi herself points out the account is still very preliminary. It does not provide answers to fundamental questions, such as what the semantics of non-RESP is or what its syntactic distribution is. Secondly, the idea of 'shielding' by non-RESP cannot be extended to NPIs since interveners like every are known to disrupt licensing of both strong and weak NPIs, see (44).

a. * Nobody gave every beggar a red cent.

(Honcoop 1998: 116)

b. * Nobody gave every beggar any money.

The second account by Zu (2018) is a purely syntactic account. Specifically, she postulates a Sentience projection (SenP) at the left periphery of attitude complements, whose specifier hosts a perspectival expression (building on ideas in Speas \& Tenny 2003). This Sen-head comes with a different featural mark-up in canonical control (RESP) and non-canonical control (non-RESP), see (45). In canonical control, Sen comes with an unvalued $\phi$-features, which triggers domain suspension (Bobaljik \& Wurmbrand 2013), making the searchable domain of canonical control as large as the matrix CP, see (45a). In non-canonical control, Sen comes only with an unvalued feature $[\mathrm{uD}]$, which is valued by PRO via Spec-head agreement and the domain is closed off at SenP, see (45b). Minimal searchable domains are underlined in (45).
a. [ ${ }_{\mathrm{CP}} \mathrm{DP}_{\mathrm{iD}, \mathrm{i} \phi} \mathrm{V}$ [SenP $\mathrm{PRO}_{\mathrm{iD}, \mathrm{u} \phi} \operatorname{Sen}_{\mathrm{uD}, \mathrm{u} \phi}\left[\mathrm{TP}_{\mathrm{PRO}} \mathrm{V}\right.$ PPI ]]] (canonical)
b. [CP DP ${ }_{\mathrm{iD}, \mathrm{i} \phi} \mathrm{V}$ [SenP $\mathrm{PRO}_{\mathrm{iD}, \mathrm{u} \phi} \operatorname{Sen}_{\mathrm{uD}}\left[\mathrm{TP} \mathrm{t}_{\mathrm{PRO}} \mathrm{V}\right.$ PPI ]]] (non-canonical) 
The difference in PPI licensing is then attributed to the locality condition, as in (46). $\mathrm{Zu}$ (2018) proposes that English control constructions are ambiguous between canonical and non-canonical control. In (45a), where RESP is present and thus, actions are interpreted as intentional, the PPI and negation appear in the same domain $(\underline{\mathrm{CP}})$ and thus, the PPI is anti-licensed. By contrast, in (45b) with no RESP, the PPI is in a separate domain $(\underline{\operatorname{SenP}})$ and thus, is not anti-licensed by negation.

(46) I don't think that [тр John called someone ]

$(\checkmark$ not $>$ some $)$

Zu's account is problematic for strong NPI licensing because it relies on syntactic domains. It is well known that neg-raising predicates, including want, create one syntactic domain (e.g., Zeijlstra 2018). Thus, Zu incorrectly predicts either the absence of the contrast in strong NPI licensing in intentional versus accidental contexts or the absence of neg-raising readings with accidental actions.

\section{Beyond the polarity system}

In this section, we will see that the effect of the interpretation of an action as intentional versus accidental has been observed in different domains of the grammar across unrelated languages. which suggests that we are dealing with a possible semantic universal. The catalogue below is not an exhaustive list of grammatical phenomena sensitive to the intepretation of an action, but it provides a good illustration of the range and richness of the effect.

In many European languages, including Hungarian, Romance, and some Slavic, the subject of the subjunctive clause cannot co-refer with the subject of the matrix clause, see (47). This restriction is known as subjunctive obviation or disjoint reference effect (Bouchard 1983; Ruwet 1984, 1991; Farkas 1992; Constantini 2006; Schlenker 2005, 2011).

(47) a. Je veux partir. 'I want to leave.'

(French)

b. * Je veux que je parte. 'I want for me to leave.'

An interesting property of subjunctive obviation is that it is weakened when the degree of agency of the embedded subject, matrix subject, or both is reduced, see (48) (Zaring 1985; Ruwet 1984; Farkas 1992).

a. Je veux absolument que j'amuse ces enfants.

(French)

'I absolutely want for me to amuse the children.'

b. Je voudrais bien que je parte tôt.

'I would like it well for me to leave early.'

c. Je voudrais bien que je puisse partir des aujourd'hui.

'I would like well that I can leave already today.'

(Farkas 1992: 88) 
Dynamic presupposition of want and polarity sensitivity

A phenomena similar to subjunctive obviation is found in Newari (Sino-Tibetan) where the disjunct inflection with co-referential subjects is normally ungrammatical, see (49a), but it becomes possible when the action is accidental or non-controlled, see (49b), e.g., Hale 1980; Wechsler 2018; Zu 2018.

a. wõ: [wa ana wan-a dhakā:] dhāla

(s)he.ERG (s)he there go-PST.DISJ that said

'(S)he ${ }_{1}$ said that $(s) h e_{* 1 / 2}$ went there.'

b. Shyam-a dhāl-a ki [wa birāmi jul-a].

Shyam-ERG say-PST.DISJ that he ill become-PST.DISJ

'Shyam 1 said that he ${ }_{1}$ became ill.'

(Zu 2018: 70,146)

Another phenomenon showing sensitivity to the interpretation of an action concerns aspect choice in Slavic. Across Slavic languages, positive imperatives can take verbs in either imperfective (IPFV) or perfective (PFV) aspect with minimal interpretative differences. Negative imperatives (and deontic modal expressions in Eastern Slavic) are generally ill-formed with perfective verbs, see (50a). However, the perfective becomes available when the action is accidental, see (50b) (Forsyth 1970; Paducheva 2013; Despić 2020).

a. Ne otkryvaj /*otkroj okno!

(Russian)

not open-IMPRF / open-PRF window

'Don't open the window!'

b. Smotri, slučajno ne otkroj okno!

look by.luck not open-PRF window

'Careful! Don't accidentally open the window!'

Some other phenomena sensitive to the interpretation of an action concern case assignment in languages that exhibit the so-called ergativity split, like Hindi/Urdu and Georgian, or have agent/patient marking, like Central Pomo (Pomoan language spoken in Northern California) (Tuite, Agha \& Graczyk 1985; Mithun 1991). For example, in Hindi/Urdu, the ergative case is used to mark subjects of intentional actions, see (51a), whereas the nominative marks subjects of accidental actions, see (51b).

a. Ram=ne khas-a.

(Hindi/Urdu)

Ram-M.ERG cough-PERF.M.SG

'Ram coughed (purposefully).'

b. Ram khas-a.

Ram-M.NOM cough-PERF.M.SG

'Ram coughed.'

(Tuite et al. 1985: 264) 
Finally, at least one language has been found that has a dedicated 'out-of-control' morpheme. In St'át'imcets/Lillooet (Salish language spoken in southern British Columbia) the circumfix $k a \ldots a$ adds a range of nuances to the interpretation of the action, including unexpectedness, ability, and accidentality, see (52) (Demirdache 1997; Davis, Matthewson \& Rullmann 2009).

a. sek'w-p ti nk'wan'ústen-a

(St'át'imcets) broken-INC DET window-DET

'The window broke.'

b. ka-sek'w-a ti nk'wan'ústen-a KA-broken-A DET window-DET

'The window was accidentally broken.'

(Demirdache 1997: 108-9)

Little research has been carried out on the phenomena described above and then only focused on individual cases or a subset of cases. No overarching theory of the linguistic underpinnings of sensitivity to the intepretation of an action has been formulated so far. Yet our ability to distinguish between actions that are done intentionally and those that are accidental is fundamental for social interaction as it allows us to plan and perform joint actions and to assign responsibility for our own actions and those of others. More research is needed in this area.

\section{Conclusion}

In this paper, we discussed novel and known observations that licensing of PSIs in control constructions with want is sensitive to the interpretation of an action as intentional versus accidental. I argued that these facts can be accounted for if we derive different presuppositions for want depending on the interpretation of the action. The mechanism that we used for deriving different presuppositions was based on the AGM paradigm for belief revision. In addition to correctly accounting for the data, the analysis proposed here successfully dealt with PSIs in object control constructions and simple unembedded sentences and also explained some restrictions that previously were just a stipulation. Finally, we saw that sensitivity of PSIs to the interpretation of an action is part of a larger picture where many grammatical phenomena are sensitive to the same distinction between intentional and accidental actions. 
Dynamic presupposition of want and polarity sensitivity

\section{References}

Alchourrón, Carlos E., Peter Gärdenfors \& David Makinson. 1985. On the logic of theory change: Partial meet contraction and revision functions. The Journal of Symbolic Logic 50(2). 510-530.

Baker, Carl Lee. 1970. Double negatives. Linguistic Inquiry 1(2). 169-186.

Bartsch, Renate. 1973. Negative transportation gibt es nicht. Linguistische Berichte 27. 1-7.

Bobaljik, Jonathan D. \& Susi Wurmbrand. 2013. Suspension across domains. In Ora Matushansky \& Alec Marantz (eds.), Distributed Morphology Today: Morphemes for Morris Halle, 185-198. Cambridge MA: MIT Press.

Bouchard, Denis. 1983. The avoid pronoun principle and the elsewhere principle. In NELS 13, 29-36. Amherst: Univeristy of Massachusetts, GLSA.

Bratman, Michael. 1987. Intentions, Plans, and Practical Reason. Cambridge, MA: Harvard University Press.

Chierchia, Gennaro. 2013. Logic in Grammar: Polarity, Free Choice, and Intervention. Oxford: Oxford University Press.

Collins, Chris \& Paul M. Postal. 2014. Classical NEG Raising. Cambridge: The MIT Press.

Condoravdi, Cleo \& Sven Lauer. 2012. Imperatives: meaning and illocutionary force. In Christopher Piñon (ed.), Empirical Issues in Syntax and Semantics, vol. 9, 37-58.

Condoravdi, Cleo \& Sven Lauer. 2016. Anankastic conditionals are just conditionals. Semantics and Pragmatics 9. 1-61.

Constantini, Francesco. 2006. Subjunctive obviation: an interface perspective: Ca' Foscari University of Venice PhD dissertation.

Davidson, Donald. 1967. The logical form of action sentences. In Nicholas Rescher (ed.), The Logic of Decision and Action, 81-95. Pittsburg: University of Pittsburg Press.

Davidson, Donald. 2001. Essays on Actions and Events. Oxford: Oxford University Press.

Davis, Henry, Lisa Matthewson \& Hotze Rullmann. 2009. 'Out of control' marking as circumstantial modality in St'át' imcets. In Lotte Hogeweg, Helen de Hoop \& Andrej Malchukov (eds.), Cross-linguistic Semantics of Tense, Aspect and Modality, 205-244. Amsterdam / Philadelphia: John Benjamins Publishing Company.

Demirdache, Hamida. 1997. 'Out of control' in Salish and event (de)composition. In A. Mendikoetxea \& M. Uribe-Etxebarria (eds.), Theoretical Issues at the Morphology-syntax Interface, 97-144.

Despić, Miloje. 2020. Negative imperatives and aspect: a phase-based approach. In 
P. Kosta \& T. Radeva-Bork (eds.), Current Developments in Slavic Linguistics: Twenty Years After, Bern: Peter Lang.

van Ditmarsch, Hans, Wiebe van der Hoek \& Barteld Kooi. 2008. Dynamic Epistemic Logic. Dordrecht: Springer.

Farkas, Donka. 1988. On obligatory control. Linguistics and Philosophy 11. 27-58. Farkas, Donka F. 1992. On obviation. In Ivan A. Sag \& Anna Szabolcsi (eds.), Lexical Matters, chap. 4, 85-110. Stanford, Calif.: Center for the Study of Language and Information.

Fillmore, Charles F. 1963. The position of embedding transformations in a grammar. Word 19. 208-231.

Forsyth, James. 1970. A Grammar of Aspect: Usage and Meaning in the Russian Verb. Cambridge: Cambridge University Press.

Gajewski, Jon. 2005. Neg-raising: polarity and presupposition: MIT PhD dissertation.

Gajewski, Jon. 2007. Neg-raising and polarity. Linguistics and Philosophy 30. 289-328.

Gajewski, Jon. 2011. Licensing strong NPIs. Natural Language Semantics 19. 109-148.

Giannakidou, Anastasia. 2011. Negative and positive polarity items: Variation, licensing, and compositionality. In P. Portner C. Maienborn, K. von Heusinger (ed.), Semantics: An International Handbook of Natural Language Meaning, Berlin: De Gruyter Mouton.

Gorr, Michael \& Terence Horgan. 1982. Intentional and unintentional actions. Philosophical Studies 41(2). 251-262.

Hale, Austin Everett. 1980. Person markers: finite conjunct and disjunct verb forms in Newari. In Ronald L Trail (ed.), South East Asian Linguistics, vol. 7, 95-106. Canberra: Australian National University.

Heim, Irene. 1992. Presupposition projection and the semantics of attitude verbs. Journal of Semantics 9. 183-221.

Homer, Vincent. to appear. Domains of polarity items. Journal of Semantics .

Honcoop, Martinus F. 1998. Dynamic excursions on weak islands: University of Leiden $\mathrm{PhD}$ dissertation.

Jackendoff, Ray. 1995. The conceptual structure of intending and volitional action. In Héctor Campos \& Paula Kempchinsky (eds.), Evolution and Revolution in Linguistic Theory, 198-227. Washington, D.C.: Georgetown University Press.

Kaufmann, Magdalena. 2019. Who controls who (or what). SALT 29 636-664.

Kaufmann, Magdalena \& Stefan Kaufmann. 2012. Epistemic particles and performativity. SALT 22 208-225.

Klima, Edward S. 1964. Negation in English. In J. A. Fodor \& J. J. Katz (eds.), The Structure of Language: Readings in the Philosophy of Language, 246-323. 
Dynamic presupposition of want and polarity sensitivity

Englewood Cliffs, N.J.: Prentice-Hall.

Kroch, Anthony S. 1979. The Semantics of Scope in English. New York: Garland. Lindström, Sten \& Wlodek Rabinowicz. 1999. DDL unlimited: Dynamic doxastic logic for introspective agents. Erkenntnis 50(2/3). 353-385.

Mithun, Marianne. 1991. Active/agentive case marking and its motivations. Language 67(3). 510-546.

Nicolae, Andreea Cristina. 2012. Positive polarity items: An alternative-based account. In Ana Aguilar Guevara, Anna Chernilovskaya \& Rick Nouwen (eds.), Sinn und Bedeutung 16, 475-488. Cambridge, MA: MITWPL.

Paducheva, Elena V. 2013. Russkoe Otricatel'noe Predlozhenie. Moscow: Jazyki slavjanskoi kul'tury.

Romoli, Jacopo. 2012. Soft but strong. neg-raising, soft triggers, and exhaustification: Harvard University PhD dissertation.

Ruwet, Nicolas. 1984. Je veux partir/* je veux que je parte. à propos de la distribution des complétives à temps fini et des compléments à l'infinitif en français. Cahiers de Grammaire 7. 75-138.

Ruwet, Nicolas. 1991. Syntax and Human Experience. Chicago: University of Chicago Press.

Schlenker, Philippe. 2005. The lazy Frenchman's approach to the subjunctive. In Romance Languages and Linguistic Theory, 269-309.

Schlenker, Philippe. 2011. Indexicality and de se reports. In Claudia Maienborn, Klaus von Heusinger \& Paul Portner (eds.), Semantics: An International Handbook of Natural Language Meaning, 1561-1604. Berlin: Mouton de Gruyter.

Speas, Peggy \& Carol Tenny. 2003. Configurational properties of point of view roles. In A. DiSciullo (ed.), Asymmetry in Grammar, 315-344. Amsterdam: John Benjamins.

Stalnaker, Robert. 1984. Inquiry. Cambridge: MIT Press.

Stalnaker, Robert C. 2002. Common ground. Linguistics and Philosophy 25. $701-721$.

Stroud, Sarah \& Larisa Svirsky. 2019. Weakness of will. In Edward N. Zalta (ed.), The Stanford Encyclopedia of Philosophy, https://plato.stanford.edu/archives/ fall2019/entries/weakness-will/.

Szabolcsi, Anna. 2004. Positive polarity - negative polarity. Natural Language and Linguistic Theory 22. 409-452.

Szabolcsi, Anna. 2010. Infinitives vs. subjunctives: What do we learn from obviation and from exemptions from obviation? URL http://goo.gl/c16gIP ms. New York University.

Tuite, Kevin J., Asif Agha \& Randolph Graczyk. 1985. Agentivity, transitivity, and the question of active typology. In Chicago Linguistic Society Parasession on Causatives and Agentivity, vol. 21 2, 252-70. 
Wechsler, Stephen. 2018. Egophoricity. Typological Studies in Language 118. 473-494.

van der Wouden, Ton. 1997. Negative Contexts: Collocation, Polarity and Multiple Negation. London, New York: Routledge.

Zaring, Laurie. 1985. The syntactic role of verbal inflection in French and Brazilian Portuguese: Cornell University PhD dissertation.

Zeijlstra, Hedde. 2018. Does Neg-Raising involve Neg-Raising. Topoi 37. 417-433.

$\mathrm{Zu}$, Vera. 2018. Discourse participants and the structural representation of the context: NYU PhD dissertation.

Zwarts, Frans. 1998. Three types of polarity. In Fritz Hamm \& Erhard W. Hinrichs (eds.), Plurality and Quantification, 177-238. Dordrecht: Kluwer Acedemic Publishers.

Julie Goncharov

Käte-Hamburger-Weg 3

37073 Göttingen

julie.goncharov@mail.utoronto.ca 